\title{
¿CUMPLE CHILE LOS ESTÁNDARES INTERNACIONALES EN MATERIA DE CONSULTA A LOS PUEBLOS INDÍGENAS? (UNA BREVE REVISIÓN A LOS D.S. No 66 DEL MINISTERIO DE DESARROLLO SOCIAL Y No 40 DEL MINISTERIO DEL MEDIO AMBIENTE) ${ }^{*}$ \\ Does CHILE MEET THE INTERNATIONAL STANDARDS IN CONSULTATION OF INDIGENOUS PEOPLES? (A BRIEF REVIEW OF THE D.S. No 66 Of THE MINISTRY OF SOCIAL DEVELOPMENT AND No 40 OF THE MINISTRY OF THE ENVIRONMENT)
}

\author{
Luis Fernando Astudillo Becerra (hijo de Alberto y Mercedes) ${ }^{* *}$ \\ fastudilloabogado@vtr.net
}

RESUMEN: La Consulta Indígena, como ha sido concebida en el Derecho Internacional, es una forma en que los pueblos expresan el derecho de decidir sus propias prioridades en lo que atañe al proceso de desarrollo, en la medida en que éste afecte a sus vidas, creencias, instituciones y bienestar espiritual $y$ a las tierras que ocupan o utilizan de alguna manera, y de controlar, en la medida de lo posible, su propio desarrollo económico, social y cultural. Además, una forma en que dichos pueblos participan en la formulación, aplicación y evaluación de los planes y programas de desarrollo nacional y regional susceptibles de afectarles directamente. También una forma de contrapesar la mirada de desarrollo con la mirada del desarrollo del Estado y de los empresarios.

El presente artículo busca, por una parte, sistematizar los estándares internacionales sobre la consulta, analizar el cumplimiento que de ellos en materia de derechos humanos y de derechos de los pueblos indigenas hace el Estado de Chile, confrontando la implementación administrativa del derecho a la consulta de los pueblos indígenas, a través esencialmente de un análisis del D.S. No 66 y del Decreto No 40 que reglamenta la Ley No 19.300 sobre Bases del Medio Ambiente, con los estándares internacionales.

ABSTRACT: Summary: Indigenous consultation, as conceived in international law, is a way in which people express the right to decide their own priorities in the development process, insofar as it affects their lives, Beliefs, institutions and spiritual well-being and to the lands they occupy or otherwise use, and to control, as far as possible, their own economic, social and cultural development. In addition, a way in which such peoples participate in the formulation, implementation and evaluation of national and

* Trabajo recibido el 9 de septiembre de 2015 y aprobado el 16 de noviembre de 2016.

** Abogado, Licenciado en Ciencias Jurídicas de la Universidad Bolivariana, Magíster en Derecho de la Universidad de Valparaíso, Doctor (c) en Derecho de la Universidad de Valparaíso. 
regional development plans and programs that may affect them directly. Also a way to counterbalance your developmental look with the look of the development of the State and the businessman.

The present article seeks, on the one hand, to systematize the international standards on the consultation, to analyze the fulfilment that of them in the matter of human rights and of rights of the indigenous peoples, does the State of Chile, confronting the administrative implementation of the right to the Consultation of indigenous peoples, essentially through an analysis of D.S. No 66 and Decree $N^{\circ} 40$, which regulates law $N^{\circ} 19.300$ on the basis of the environment, with international standards.

PALABRAS CLAVE: Consulta Indigena, derechos humanos, derecho internacional.

KEYWORDS: Indigenous Consultation, human rights, international law.

\section{INTRODUCCIÓN}

Este estudio se centrará en sistematizar cuáles son los estándares internacionales sobre el derecho a la Consulta Indígena, a través del examen de la jurisprudencia del sistema interamericano y de las opiniones que han emanado de órganos o instituciones autorizadas en el seno de las Naciones Unidas de la Organización Internacional del Trabajo.

Se revisará el grado de cumplimiento de estos estándares en Chile, sobre la base de un análisis de las normas reglamentarias contenidas en el Decreto Supremo, en adelante D.S. No 66 de 2013 y en adelante el Reglamento, sobre Consulta Indígena, además del D.S. No 40 de 2013, que reglamenta la Ley No 19.300 sobre Bases Generales del Medio Ambiente.

Hechas estas consideraciones, hago presente que el trabajo lo he dividido en tres partes: en la primera me referiré a las normas de Derecho Internacional que resultan aplicables al caso de la consulta desde la perspectiva de los pronunciamientos que al respecto han realizado tanto la Comisión Interamericana de Derechos Humanos como la Corte Interamericana de Derechos Humanos, todo sobre la base del Convenio 169 de la Organización Internacional del Trabajo, en adelante OIT. En la segunda, me referiré a los requisitos de la consulta (que se desprenden del análisis de la primera parte) y, en la tercera, analizaré y contrastaré todo lo anterior con los reglamentos que se refieren a la Consulta, ya citados en el presente trabajo.

Todo para defender la tesis que la Consulta como ha sido planteada por el Estado de Chile, en el D.S. No 66 de 2013 del Ministerio de Desarrollo Social y en el D.S. No 40 de 2013 del Ministerio del Medio Ambiente, no cumple con los estándares establecidos en el Derecho Internacional y tampoco con las condiciones que respecto de ella han establecido numerosos pronunciamientos de la Corte Interamericana de Derechos Humanos, en adelante Corte IDH y de la Comisión Interamericana de Derechos Humanos, en adelante CIDH. 


\section{Normas de Derecho Internacional aplicables, pronunciamientos de la CorTe IDH y de la CIDH}

Son varias las normas que se refieren a la obligación de los Estados de consultar a los pueblos indígenas sobre legislación o decisiones administrativas que les puedan afectar. Éstas las contemplan especialmente el Convenio 169 de la OIT ${ }^{1}$ y la Declaración de las Naciones Unidas sobre los Derechos de los Pueblos Indígenas ${ }^{2}$, pero como veremos no sólo de estos instrumentos jurídicos se desprende esta obligación.

El artículo 6 del Convenio 169 señala que los Estados deben consultar a los pueblos indígenas "mediante procedimientos apropiados y en particular a través de sus instituciones representativas, cada vez que se prevean medidas legislativas o administrativas susceptibles de afectarles directamente" 3 . Señala además la norma, la forma, el fondo y el objetivo que resulta deseable obtener de ellas; deben ser llevadas a cabo "de buena fe y de una manera apropiada a las circunstancias, con la finalidad de llegar a un acuerdo o lograr el consentimiento acerca de las medidas propuestas" 4 .

Otra norma que es necesario tener en cuenta en relación a la consulta es el artículo 19 de la Declaración de Naciones Unidas sobre el Derecho de los Pueblos Indígenas, que en términos generales se refiere a ella del siguiente modo: "Los Estados celebrarán consultas y cooperarán de buena fe con los pueblos indígenas interesados por medio de sus instituciones representativas antes de adoptar y aplicar medidas legislativas o administrativas que los afecten, a fin de obtener su consentimiento libre, previo e informado" 5 .

Se desprende de lo analizado hasta ahora que el derecho a la consulta y el deber estatal de realizarla se vinculan con el derecho a la participación, consagrado en el artículo 23 de la Convención Americana de Derechos Humanos ${ }^{6}$, que reconoce el derecho de todos los ciudadanos a participar en la dirección de los asuntos públicos, directamente o por medio de representantes.

Por su parte, la Corte Interamericana de Derechos Humanos interpretó este artículo, en el caso del pueblo indígena Yatama vs. Nicaragua, señalando que en

1 El Convenio 169 de la OIT obliga a los Estados a consultar con los pueblos indígenas, de buena fe y con el objetivo de llegar a un acuerdo u obtener su consentimiento, sobre asuntos que les afectan en distintos contextos; ver los arts. 6.1, 6.2, 15.2, 22.3, 27.3 y 28 del Convenio.

2 Entre otros, los artículos 10, 11, 15, 17, 19, 28, 29, 30, 32, 36 y 38 de la Declaración de la ONU.

3 Convenio 169 de la OIT, artículo 6.1.a).

4 Convenio 169 de la OIT, artículo 6.2.

5 Declaración de las Naciones Unidas sobre los Pueblos Indígenas, art. 19.

6 Convención Americana Derechos Humanos, art. 23. 
el contexto de los pueblos indígenas, el derecho a la participación política incluye el derecho a "participar en la toma de decisiones sobre asuntos y políticas que inciden o pueden incidir en sus derechos... desde sus propias instituciones y de acuerdo a sus valores, usos, costumbres y formas de organización”7.

En esta misma línea, pero ya derechamente sobre la Consulta, se ha manifestado la Comisión Interamericana de Derechos Humanos, señalando que "uno de los elementos centrales para la protección de los derechos de propiedad de los indígenas, es el requisito de que los Estados establezcan consultas efectivas y previamente informadas con las comunidades indígenas en relación con los actos y decisiones que puedan afectar sus territorios tradicionales" 8 .

Todo lo anterior, la Consulta, el derecho a la participación política, se relaciona directamente con el derecho a la identidad cultural de los pueblos indígenas, en la medida en que la cultura y las formas de vida de los pueblos indígenas pueden resultar afectadas por las decisiones que se someten a consulta9.

Porque, tanto el Convenio 169 como la Declaración de las Naciones Unidas sobre los Pueblos Indígenas establecen que es deber del Estado respetar, proteger y promover las tradiciones y costumbres de los pueblos indígenas y tribales, por ser éstas un componente intrínseco de la identidad cultural de las personas que conforman tales pueblos. De esta obligación estatal surge la necesidad de adoptar medidas especiales para proteger este derecho a la identidad cultural, basado en una forma de vida intrínsecamente ligada al territorio ${ }^{10}$.

Otro elemento central que es preciso aclarar es que el objetivo de la Consulta no es otro que obtener el consentimiento libre e informado del pueblo indígena sobre las materias que les afectarán ${ }^{11}$. El deber de consultar con el fin de obtener el consentimiento se reitera en varias disposiciones específicas de la Declaración de las Naciones Unidas sobre los Derechos de los Pueblos Indígenas ${ }^{12}$. Debe tener el objetivo de alcanzar un acuerdo, o de recibir el consentimiento informado de

7 Corte IDH, Caso Yatama vs. Nicaragua. Sentencia de 23 de junio de 2005, párr. 225.

$8 \mathrm{CIDH}$, Informe No 40/04, Caso 12.053, Comunidades Indígenas Mayas del Distrito de Toledo (Belice), 12 de octubre de 2004, párr. 142.

9 Aguilar (2006), pp. 106-119.

10 CIDH, Democracia y Derechos Humanos en Venezuela. Doc. OEA 54, 30 de diciembre de 2009, párr. 1050.

11 CIDH, "Informe de Seguimiento - Acceso a la Justicia e Inclusión Social: El camino hacia el fortalecimiento de la Democracia en Bolivia”. Doc. OEA. 40, 7 de agosto de 2009, párr. 158.

12 Declaración de Naciones Unidas sobre los Pueblos Indígenas, artículos 10, 11, 15, 17, 19, 28, 29, 30, 32,36 y 38. 
los pueblos indígenas a los planes de desarrollo o inversión o las concesiones extractivas que puedan afectar su derecho de propiedad sobre las tierras, territorios y recursos naturales ${ }^{13}$. Al decir de la Corte Interamericana, como regla general, los Estados deben "garantizar, a través de procedimientos claros de consulta, que se obtenga su consentimiento previo, libre e informado para la consecución de dichos proyectos". La obligación primaria de los Estados es la de asegurar, en consonancia con el Convenio 169 de la OIT, "que todo proyecto de infraestructura o de explotación de recursos naturales en área indígena o que afecte su hábitat o cultura, sea tramitado y decidido con participación y en consulta con los pueblos interesados con vistas a obtener su consentimiento y eventual participación en los beneficios" 14 .

Por lo que el logro de dicho objetivo supondrá que cualquier decisión administrativa que pueda afectar jurídicamente los derechos o intereses de los pueblos indígenas y tribales sobre sus territorios debe estar basada en un proceso de participación plena ${ }^{15}$.

\section{Requisitos esenciales de la Consulta}

Por lo dicho, hasta ahora, se puede obtener una primera conclusión: No cualquier acto de consulta puede interpretarse como un acto que responde a la obligación de

13 El Relator Especial de la ONU ha precisado en esta línea que "[e]n todos los casos en que una medida propuesta afecte los intereses particulares de los pueblos indígenas, la obtención de su consentimiento deberá ser, en cierta medida, una finalidad de las consultas. (...) esta exigencia no confiere a los pueblos indígenas un 'poder de veto' sino que, más bien, establece la necesidad de elaborar procedimientos de consulta con el fin de hacer todo lo posible por lograr el consenso de todas las partes interesadas. (...) Esos principios [de consulta y consentimiento] han sido concebidos para crear un diálogo en que los Estados y los pueblos indígenas puedan trabajar de buena fe con miras al logro del consenso y procuren seriamente llegar a un acuerdo satisfactorio. (...) el deber de los Estados de celebrar consultas con los pueblos indígenas y los principios conexos ha surgido para poner fin a modelos históricos de decisiones que se han impuesto a los pueblos indígenas y a condiciones de vida que han amenazado su supervivencia. Al mismo tiempo, los principios de consulta y consentimiento no confieren a los pueblos indígenas un derecho a imponer unilateralmente su voluntad a los Estados que actúan legítimamente y de buena fe en bien del interés del público. Los principios de consulta y consentimiento están más bien encaminados a evitar que se imponga la voluntad de una parte sobre la otra y a que, en lugar de ello, se procure llegar a un entendimiento mutuo y adoptar decisiones por consenso". ONU -Consejo de Derechos Humanos- Informe del Relator Especial sobre la situación de los derechos humanos y las libertades fundamentales de los indígenas, James Anaya. Doc. ONU, 15 de julio de 2009, párrs. 48-49.

14 CIDH, Segundo Informe sobre la Situación de los Derechos Humanos en el Perú. Doc. OEA 59 rev., 2 de junio de 2000, Capítulo X, párr. 39 - Recomendación 5.

15 Torrecuadrada (2010). 
consultar que establecen, para los Estados, las normas internacionales. De este modo entramos al segundo punto de este artículo: la Consulta deberá cumplir con ciertos requisitos, dichos requisitos serán los que darán legalidad y legitimidad a la misma.

\subsection{Que la Consulta efectivamente sea previa}

Esto es que ella debe llevarse a cabo en la etapa de exploración o de planificación del proyecto, con la suficiente anticipación al inicio de las actividades de ejecución. Los procedimientos de consulta se deben desarrollar "antes de diseñar y ejecutar proyectos de explotación de recursos naturales en las tierras y territorios ancestrales de los pueblos indígenas"16; "no únicamente cuando surja la necesidad de obtener la aprobación de la comunidad, si éste fuera el caso. El aviso temprano proporciona un tiempo para la discusión interna dentro de las comunidades y para brindar una adecuada respuesta al Estado"17.

En este mismo sentido se ha pronunciado James Anaya, Relator Especial de la ONU para los pueblos indígenas, al señalar que "en todos los casos en que se aplique el deber de celebrar consultas su finalidad deberá ser obtener el consentimiento o el acuerdo de los pueblos indígenas afectados. De ahí que las consultas deban realizarse en las primeras etapas de la elaboración o planificación de la medida propuesta a fin de que los pueblos indígenas puedan verdaderamente participar e influir en el proceso de adopción de decisiones" 18.

\subsection{Que la Consulta responda a la cultura del pueblo indigena al que se consulta}

La Corte Interamericana de Derechos Humanos ha señalado que el deber estatal de consultar a los pueblos indígenas debe cumplirse de acuerdo con sus costumbres y tradiciones, a través de procedimientos culturalmente adecuados y teniendo en cuenta sus métodos tradicionales para la toma de decisiones ${ }^{19}$. Lo anterior es varias

$16 \mathrm{CIDH}$, Acceso a la Justicia e Inclusión Social: El camino hacia el fortalecimiento de la Democracia en Bolivia. Doc. OEA 34, 28 de junio de 2007, párr. 249.

17 Corte IDH. Caso del Pueblo Saramaka vs. Surinam. Excepciones Preliminares, Fondo, Reparaciones y Costas. Sentencia de 28 de noviembre de 2007, párr. 133.

18 ONU - Consejo de Derechos Humanos - Informe del Relator Especial sobre la situación de los derechos humanos y libertades fundamentales de los indígenas, James Anaya. Doc. ONU, 15 de julio de 2009, párr. 65.

19 Corte IDH, Caso del Pueblo Saramaka vs. Surinam. Excepciones Preliminares, Fondo, Reparaciones y Costas. Sentencia de 28 de noviembre de 2007, párr. 131. 
veces reiterado por la Corte Interamericana de Derechos Humanos al resolver el Caso del Pueblo Saramaka vs. Surinam, señalando que los Estados deben permitir la participación efectiva de los pueblos indígenas y tribales, de conformidad con sus tradiciones y costumbres, en los procesos de toma de decisiones respecto de las concesiones extractivas o de los planes o proyectos de desarrollo o inversión; se violan los artículos 21 y 1.1 de la Convención Americana al no hacerlo ${ }^{20}$.

La regla de adecuación cultural de la Consulta exige que la representación de los pueblos indígenas sea definida de conformidad con sus propias tradiciones; según la Corte Interamericana en el caso del pueblo Saramaka, "al declarar que la consulta se debe realizar 'de conformidad con sus costumbres y tradiciones', la Corte reconoció que es el pueblo Saramaka, y no el Estado, quien debe decidir sobre quién o quiénes representarán al pueblo Saramaka en cada proceso de consulta ordenado por el Tribunal"21. En consecuencia, "el pueblo Saramaka debe informar al Estado quién o quiénes lo representarán en cada uno de los procesos de consulta señalados anteriormente. El Estado deberá consultar con tales representantes a fin de cumplir con lo ordenado por el Tribunal”. Estos requisitos tienen una clara base normativa en los principales instrumentos internacionales de derechos humanos. Así, lo señala el artículo 6.1 del Convenio 169 de la OIT que indica que se requiere que las consultas se lleven a cabo "mediante procedimientos apropiados y en particular a través de sus instituciones representativas" 22 .

\subsection{Deben usarse procedimientos adecuados}

Es de primerísima importancia que los Estados, y valga la redundancia, consulten sobre los procedimientos de consulta, se desprende esta obligación del artículo recién citado del Convenio 169, también tienen la obligación general de consultar a los pueblos indígenas sobre los procedimientos de consulta ${ }^{23}$. El

20 Corte IDH. Caso del Pueblo Saramaka vs. Surinam. Excepciones Preliminares, Fondo, Reparaciones y Costas. Sentencia de 28 de noviembre de 2007, párr. 154.

21 Corte IDH. Caso del Pueblo Saramaka vs. Surinam. Interpretación de la Sentencia de Excepciones Preliminares, Fondo, Reparaciones y Costas. Sentencia de 12 de agosto de 2008, párr. 18.

22 Convenio 169 , artículo 6.1.

23 Cfr. Convenio 169 de la OIT, artículo 6.1 (a) (los Estados deberán "consultar a los pueblos interesados... cada vez que se prevean medidas legislativas o administrativas susceptibles de afectarles directamente"); Declaración de Naciones Unidas, artículo 19 ("Los Estados celebrarán consultas y cooperarán de buena fe con los pueblos indígenas interesados... antes de adoptar medidas legislativas o administrativas que los afecten”). Según el Relator Especial de la ONU, “[n]o obstante el carácter necesariamente variable de los 
cumplimiento del deber de consultar a los pueblos indígenas y tribales sobre la definición del marco legislativo e institucional de la consulta previa, es una de las medidas especiales requeridas para promover la participación de los pueblos indígenas en la adopción de las decisiones que les afectan directamente ${ }^{24}$.

En palabras de James Anaya, Relator Especial de la ONU, "en los casos relativos a explotación de recursos naturales o proyectos de desarrollo que afecten tierras indígenas, para que los pueblos indígenas interesados puedan adoptar decisiones libres e informadas sobre el proyecto en consideración es necesario que reciban información objetiva y completa sobre todos los aspectos del proyecto que los afecta, incluidas las repercusiones del proyecto sobre su vida y su entorno. A este respecto, es esencial que el Estado haga estudios sobre el impacto ambiental y social a fin de que se puedan conocer todas las consecuencias que cabe prever. Los grupos indígenas interesados deben conocer esos estudios de impacto en las primeras etapas de las consultas, tener tiempo suficiente para entender las conclusiones de los estudios y poder presentar sus observaciones y recibir información acerca de cualquier preocupación que planteen" 25 .

\subsection{La Consulta debe hacerse a través de sus instituciones representativas}

La Declaración de Naciones Unidas exige que las consultas se celebren "por medio de sus instituciones representativas"26.

Por lo que la representación del pueblo durante los procesos de consulta debe ser la que determine el propio pueblo y habiendo tenido en cuenta la voluntad de la totalidad del pueblo expresada y canalizada, a través de los mecanismos

procedimientos de consulta en los diversos contextos, los Estados deben definir en la ley los procedimientos de consulta requeridos para determinadas categorías de actividades, como las de extracción de recursos naturales, que se realizan en territorios indígenas o que los afectan. Dichos procedimientos, previstos en leyes o reglamentos o en mecanismos especiales de consulta, deben por su parte ser elaborados en consulta con los pueblos indígenas". ONU - Consejo de Derechos Humanos - Informe del Relator Especial sobre la situación de los derechos humanos y las libertades fundamentales de los indígenas, James Anaya. Doc. ONU, 15 de julio de 2009, párr. 67.

24 Henríquez (2013), pp. 268-264.

25 ONU -Consejo de Derechos Humanos- Informe del Relator Especial sobre la situación de los derechos humanos y las libertades fundamentales de los indígenas, James Anaya. Doc. ONU, 15 de julio de 2009, párr. 53.

26 Declaración de Naciones Unidas, artículo 32. 
consuetudinarios que resulten aplicables, esto es, en armonía con lo que es su tradición ${ }^{27}$.

\subsection{La Consulta de buena fe, con la finalidad de llegar a un acuerdo}

El énfasis puesto por la regulación internacional y regional sobre la buena fe en el cumplimiento del deber estatal de Consulta a los pueblos indígenas busca establecer una garantía frente a los procesos de Consulta meramente formales, una práctica frecuente que ha sido denunciada por los pueblos indígenas $28-29-30-31$. Los procesos de Consulta no equivalen al cumplimiento de una serie de requisitos pro forma ${ }^{32}$.

Por lo razonado hasta ahora, resulta claro que la Corte Interamericana de Derechos Humanos cree y así lo ha resuelto, que los procedimientos de Consulta, en tanto medios para garantizar el derecho de los pueblos indígenas y tribales a participar en los asuntos que pueden afectarles, deben estar diseñados para propender por la obtención del consentimiento libre e informado de los pueblos y no limitarse únicamente a una notificación o a un trámite de cuantificación de daños ${ }^{33}$.

La Consulta de buena fe exige la ausencia de cualquier tipo de coerción por parte del Estado ${ }^{34}$.

La Consulta de buena fe exige que ésta sea informada, con el tiempo necesario y a través de los canales más propios de comunicación y organización del pueblo. Del mismo modo, puede requerirse que el Estado suministre a dichos pueblos otros medios, que pueden incluir asistencia técnica e independiente, con miras a

27 Trentavizi (2011), pp. 5-7.

28 Radiouchile.cl. 23 de noviembre de 2013: "Comunidades critican firma del Reglamento de Consulta Indígena: Es un acto de mala fe".

29 https://eltarapaca.wordexpress.com. 27 de enero de 2015: "Denuncia de comunidades indígenas de la Región de Atacama respecto del proceso de Consulta Indígena”.

30 www.semillasdeagua.cl. 11 de septiembre de 1973: "Pueblos originarios rechazan decretos 66 y 40 impulsados por gobierno para sacar la Consulta Indígena”.

31 www.mapuexpress.net. 31 de febrero de 2009: "Aymaras califican como un acto de mala fe la pseudo consulta que realizan Conadi y el Comisionado”.

32 URrutia (2015), pp. 327-335.

33 LePpe (2015), pp. 369-383.

34 INDH (2011), pp. 10 y 11. 
que los pueblos indígenas tengan la capacidad de adoptar decisiones plenamente informadas ${ }^{35}$.

La buena fe es incompatible con prácticas tales como los intentos de desintegración de la cohesión social de las comunidades afectadas, entre otras formas, esto sucede al poner a tribus, clanes, familias o personas en competencia y/o antagonismo para que el Estado les reconozca a unos y no a otros, un determinado derecho ${ }^{36}$.

En este sentido, la Consulta de buena fe requiere el establecimiento de un clima de confianza mutua entre las partes, basado en el principio de respeto mutuo que propicie un diálogo productivo, para el logro de este fin es indispensable que la definición y aplicación del procedimiento consultivo sea el resultado de un consenso. De otro modo el procedimiento de consulta no será efectivo ni gozará de la confianza de los pueblos indígenas ${ }^{37}$.

En tanto proceso que involucra a dos partes, la Consulta de buena fe tiene asimismo una serie de implicaciones para los propios pueblos indígenas. Como partes en procesos de negociación y diálogo de buena fe en el marco del deber estatal de consultar, los pueblos indígenas tienen la responsabilidad de organizarse, definir un ideario común o representativo de la mayoría del pueblo, elegir a mandatarios que sean representativos de su historia y del querer y sentir del pueblo, y participar activamente en dichos $\operatorname{procesos}^{38}$.

35 Convenio 169, artículo 12. El apoyo técnico a los pueblos indígenas en el contexto de los procedimientos de consulta puede también interpretarse como uno de los requisitos de la provisión de medios para que los pueblos indígenas puedan ejercer plenamente su derecho a la autonomía. Convenio 169, artículo 6.1.(c). El Relator Especial de la ONU indica en este sentido que "por lo general los pueblos indígenas se encuentran en desventaja en cuanto a influencia política, recursos financieros, acceso a la información y educación pertinente con respecto a las instituciones estatales o las partes del sector privado, como las empresas, que son sus contrapartes en las consultas. (...) los Estados deben tratar debidamente de superar el desequilibrio de poder, garantizando a los pueblos indígenas la asistencia financiera, técnica y de otro tipo que necesiten y haciéndolo sin utilizar dicha asistencia como palanca o para influir en las posiciones de los indígenas en las consultas". ONU - Consejo de Derechos Humanos - Informe del Relator Especial sobre la situación de los derechos humanos y las libertades fundamentales de los indígenas, James Anaya. Doc. ONU, 15 de julio de 2009, párrs. 50-51.

36 Sentencia Corte Interamericana de Derechos Humanos, caso Kincha de Sarayaku con Ecuador, 27 de junio de 2012, párrafo 186, indica: "la misma consulta de buena fe es incompatible con prácticas tales como los intentos de desintegración de la cohesión social de las comunidades afectadas, sea a través de la corrupción de los líderes comunales o del establecimiento de liderazgos paralelos, o por medio de negociaciones con miembros individuales de las comunidades que son contrarias a los estándares internacionales".

37 Alva (2014), pp. 77-78.

38 Aninat (2014), p. 6. 


\section{El Decreto Supremo No 66}

de 15 de noviembre de 2013 y el Decreto Supremo No 40 de 2013

\subsection{Antecedentes}

El Estado de Chile en cumplimiento de lo señalado en el artículo 34 de la Ley No 19.253, que establece el deber de los servicios de la administración del Estado y de las organizaciones de carácter territorial de escuchar y considerar la opinión de las organizaciones indígenas reconocidas en la ley cuando se traten materias que tengan injerencia o relación con éstas, reglamentó la Consulta, primero por el D.S. No 124 de 2009 , decreto que fue objeto de múltiples críticas ${ }^{39}$. Entre otros, de la comisión de expertos de la OTI, quien señaló al Gobierno, en su oportunidad, sus observaciones en relación con el Convenio 169 y las disposiciones del Decreto Supremo No 124, las cuales esencialmente eran:

a) Los artículos 16 y 21 del decreto parecen dejar la decisión a los órganos administrativos, en cuanto a la pertinencia de iniciar el proceso de consulta o de participación;

b) El artículo $7^{\circ}$ del decreto parece limitar la Consulta a aquellos casos que [...] diga[n] relación exclusiva con las tierras indígenas o áreas de desarrollo indígena [...] o se refiera[n] a una mayoría significativa de comunidades, asociaciones y organizaciones indígenas determinadas o determinables;

c) El artículo 14 parece limitar la consulta a la concepción de las medidas administrativas o legislativas;

39 - El Decreto No 124 es una norma dictada por el Ejecutivo, que transgrede los artículos 6 No 1 letra a) y No 2 y 7 No 1, oración segunda, y artículo 15 del Convenio No 169, que forman parte de la legislación vigente desde su ratificación y son autoejecutables. • Transforma la Consulta en un mero proceso de difusión de las medidas propuestas desde el Estado para recoger opinión y comentarios indígenas. - Suplanta a las organizaciones representativas de los pueblos indígenas, adjudicando al Consejo de Conadi, entidad estatal, una supuesta representación. • Limita geográficamente la obligación de consultar sólo a los casos ubicados en áreas de desarrollo indígena o tierras indígenas, excluyendo situaciones que afectan tierras, recursos y territorios reclamados. - Deja al arbitrio de las autoridades el determinar cuándo corresponde o no realizar una "Consulta", dejando la adopción de medidas a la "ponderación" y arbitrio de las mismas autoridades. - Impone plazos y procedimientos inapropiados, y permite casos aberrantes como cuestionarios a responder por internet, pretendiendo que la no respuesta implica aceptación. - Introduce una arbitraria distinción local entre "actos" y "medidas administrativas", dejando fuera de las consultas a una inmensa mayoría de decisiones administrativas que afectan a los pueblos indígenas. - No contempla un procedimiento para un diálogo de buena fe tendiente a acuerdos. En encuentro de autoridades tradicionales y dirigentes indígenas 2011, resoluciones texto anexo de argumentación: http://www.politicaspublicas.net/panel/c169noticias/742declaracion-encuentro-mayo2011.html. 
d) El artículo 15 del decreto parece adolecer de falta de claridad al establecer excepciones en cuanto a los casos de emergencia "o de las necesidades de buen funcionamiento del respectivo órgano" 40 .

Luego, el 15 de noviembre de 2013, ante las múltiples críticas que recibió el Decreto Supremo No 124, de parte de expertos de la OIT, de la doctrina y especialmente de los pueblos indígenas, éste fue derogado por el D.S. No 66 promulgado el quince de noviembre de 2013 y publicado en el Diario Oficial el cuatro de marzo de 2014, sobre la Consulta Indígena, el que resultó en términos prácticos, en opinión del autor por lo que fundamentará, un nuevo retroceso en relación a las normas de Decreto No 124 y en relación a la obligación de consultar establecida en el Convenio 169 de la OIT.

\subsection{Análisis de los reglamentos Nos. 66 y 40 de 2013}

El Decreto Supremo No 66 no se puede analizar sin hacer necesaria referencia al D.S. No 40 que remite la consulta indígena al sistema de evaluación de impacto ambiental, de estos dos cuerpos normativos se desprenden graves deficiencias:

a) Se crean sin una real y efectiva participación de los pueblos indígenas ${ }^{41}$, en una materia que será central en el ejercicio de los derechos que les otorga tanto el pacto 169 de la OIT, como la Declaración de las Naciones Unidas sobre los Derechos de los Pueblos Indígenas y ahora la Declaración Americana sobre los Derechos de los Pueblos Indígenas.

b) Se excluyen del reglamento los proyectos de inversión, los que se reglamentan a través del D.S. No 40 de 2013 que complementa la Ley No 19.300 sobre Bases Generales del Medio Ambiente. No obstante lo numeroso de ellos y la importancia que tiene para su concreción la Consulta, toda vez que estos se proyectan en territorios indígenas ${ }^{42}$. El reglamento los remite al Sistema de Evaluación de Impacto Ambiental; esta es una grave deficiencia, porque no da cuenta en el Reglamento de la existencia de uno de los factores de principal desencuentro entre el Estado y los pueblos indígenas: Las diferentes y contra-

40 Solicitud directa de la comisión de expertos de la OIT. http://www.politicaspublicas.net/panel/chileoit/737-ceacr-solicitud-directa-chile.html.

41 Declaración pública de autoridades ancestrales y dirigentes de los pueblos indígenas, 2014. http:// www.indh.cl/declaracion-publica-de-autoridades-ancestrales-y-dirigentes-de-los-pueblos-indigenasautoconvocados\#sthash.xwRY4am9.dpuf.20, numerales romanos I y II.

42 Abogabir (2014), pp. 51-61. 
puestas concepciones que se tiene sobre la idea de desarrollo y sobre el uso de la tierra ${ }^{43}$.

Un reflejo de ello es la participación nula de los pueblos indígenas en las negociaciones entre el Estado y los empresarios. Los pueblos indígenas no han podido participar de forma activa en las decisiones que competen a su pueblo, los beneficios que se obtienen de la explotación de la tierra y su subsuelo y, por último, la real posibilidad de negarse a la intervención de empresas de privadas o estatales en su territorio ${ }^{44}$.

Esto está expresado en el D.S. No 66 en su artículo $8^{\circ}$ inciso 1, primera parte, que señala: "la resolución de calificación ambiental de los proyectos o actividades que ingresan al Sistema de Evaluación de Impacto Ambiental, de conformidad a lo establecido en el artículo 10 de la Ley No 19.300, y que requieran un proceso de consulta indígena... se consultarán de acuerdo a la normativa del Sistema de Evaluación de Impacto Ambiental”.

La norma recién transcrita se ve complementada por lo establecido en el artículo 85 del Decreto Supremo No 40 que indica:

"Sin perjuicio de lo establecido en el artículo 83 de este Reglamento, en el caso que el proyecto o actividad genere o presente alguno de los efectos, características o circunstancias indicados en los artículos $7^{\circ}, 8^{\circ}$ y 10 de este Reglamento, en la medida que se afecte directamente a uno o más grupos humanos pertenecientes a pueblos indígenas el Servicio deberá, de conformidad al inciso segundo del artículo $4^{\circ}$ de la Ley, diseñar y desarrollar un proceso de consulta de buena fe, que contemple mecanismos apropiados según las características socioculturales propias de cada pueblo y a través de sus instituciones representativas, de modo que puedan participar de manera informada y tengan la posibilidad de influir durante el proceso de evaluación ambiental. De igual manera, el Servicio establecerá los mecanismos para que estos grupos participen durante el proceso de evaluación de las aclaraciones, rectificaciones y/o ampliaciones de que pudiese ser objeto el Estudio de Impacto Ambiental".

Por lo tanto, los proyectos con impacto ambiental que dan lugar a la Consulta son aquellos sometidos a evaluación vía estudio de impacto ambiental; sólo cuando presentan los "efectos, características o circunstancias" que señalan las

43 Pueblos Indígenas y los ODM. PUND Colombia. 2014. Fondo para el logro de los ODM, pp. 58-62.

44 Comisión Jurídica para el autodesarrollo de los pueblos originarios andinos, marzo, 2010. Nos. 11, 12, 13,17 y 19, en www2.ohchr.org7english/issues/indigenous/.../3rd/docs/.../MEDPS.doc. 
letras c), d) y f) del artículo 11 de la Ley No $19.300^{45}$; y que sean o se espera que sean causantes de la afectación directa de uno o más pueblos indígenas o grupos humanos pertenecientes a éstos.

El artículo $7^{\text {o }}$ señala que es afectación directa ${ }^{46}$; sin embargo, este concepto no tiene necesariamente relación con lo que son las principales preocupaciones de los pueblos indígenas, esto es, la cautela de su patrimonio cultural, territorial y de sus recursos.

En relación con el último criterio, el reglamento omite su deber de consultar y de esta forma irrespeta el Convenio 169 de la OIT en sus artículos 13, 14, 15 y 16, que establecen con claridad la relación intrínseca de los territorios con la cultura de los pueblos indígenas y el respeto que los Estados deben a sus tierras ${ }^{47}$.

45 Ley No 19.300, art. 11 letras c), d), f): “c) Reasentamiento de comunidades humanas, o alteración significativa de los sistemas de vida y costumbres de grupos humanos; d) Localización en o próxima a poblaciones, recursos y áreas protegidas, sitios prioritarios para la conservación, humedales protegidos y glaciares, susceptibles de ser afectados, así como el valor ambiental del territorio en que se pretende emplazar;... f) Alteración de monumentos, sitios con valor antropológico, arqueológico, histórico y, en general, los pertenecientes al patrimonio cultural".

46 D.S. No 66 art. 7 o incisos 2 y 3: "Son medidas legislativas susceptibles de afectar directamente a los pueblos indígenas los anteproyectos de ley y anteproyectos de reforma constitucional, ambos iniciados por el Presidente de la República, o la parte de éstos cuando sean causa directa de un impacto significativo y específico sobre los pueblos indígenas en su calidad de tales, afectando el ejercicio de sus tradiciones y costumbres ancestrales, prácticas religiosas, culturales o espirituales, o la relación con sus tierras indígenas. Son medidas administrativas susceptibles de afectar directamente a los pueblos indígenas aquellos actos formales dictados por los órganos que formen parte de la Administración del Estado y que contienen una declaración de voluntad, cuya propia naturaleza no reglada permita a dichos órganos el ejercicio de un margen de discrecionalidad que los habilite para llegar a acuerdos u obtener el consentimiento de los pueblos indígenas en su adopción, y cuando tales medidas sean causa directa de un impacto significativo y específico sobre los pueblos indígenas en su calidad de tales, afectando el ejercicio de sus tradiciones y costumbres ancestrales, prácticas religiosas, culturales o espirituales, o la relación con sus tierras indígenas".

47 Convenio No 169 de la OIT, arts. 14 y 15 :

"Art. 14.1. Deberá reconocerse a los pueblos interesados el derecho de propiedad y de posesión sobre las tierras que tradicionalmente ocupan. Además, en los casos apropiados, deberán tomarse medidas para salvaguardar el derecho de los pueblos interesados a utilizar tierras que no estén exclusivamente ocupadas por ellos, pero a las que hayan tenido tradicionalmente acceso para sus actividades tradicionales y de subsistencia. A este respecto, deberá prestarse particular atención a la situación de los pueblos nómadas y de los agricultores itinerantes. 2. Los gobiernos deberán tomar las medidas que sean necesarias para determinar las tierras que los pueblos interesados ocupan tradicionalmente y garantizar la protección efectiva de sus derechos de propiedad y posesión. 3. Deberán instituirse procedimientos adecuados en el marco del sistema jurídico nacional para solucionar las reivindicaciones de tierras formuladas por los pueblos interesados. Artículo 151. Los derechos de los pueblos interesados a los recursos naturales existentes en sus tierras deberán protegerse especialmente. Estos derechos comprenden el derecho de esos pueblos a participar en la utilización, administración y conservación de dichos recursos. 2. En caso de 
Pero no son sólo estas sus deficiencias, hagamos una revisión del articulado de los D.S. en estudio, sobre la base de lo que describimos en la segunda parte de este artículo como los requisitos esenciales de la Consulta Indígena:

\subsubsection{Consulta efectivamente previa}

La Consulta puede ser decretada de oficio por el órgano responsable, o a solicitud fundada de cualquier persona interesada o institución representativa, sin perjuicio que la Corporación Nacional de Desarrollo Indígena pueda solicitar se evalúe la procedencia de iniciar un proceso.

Es necesario tener presente que el artículo 6 del Convenio No 169 establece como un deber de los Estados el consultar, por lo que recae sobre los gobiernos la dirección y el desarrollo de los procesos de consulta ${ }^{48}$. En los procesos de evaluación de impacto ambiental no serán de cargo de los titulares de los proyectos o actividades sometidos al Sistema de Evaluación de Impacto Ambiental, sino del órgano de la Administración del Estado que intervenga en aquél.

En el Reglamento que se regula el procedimiento de consulta se enumera a los órganos a los cuales se aplica, estos son "los ministerios, las intendencias, los gobiernos regionales, las gobernaciones y los servicios públicos creados para el cumplimiento de la función administrativa”. Sin embargo quedan fuera de estos órganos instituciones fundamentales dentro del aparato de la administración del Estado, como son, por ejemplo, las Municipalidades.

En lo concreto, el artículo 85 del D.S. No 40 y el artículo $8^{\circ}$ del D.S. No 66 establecen que las Consultas Indígenas en los casos que proponen se harán de acuerdo a la normativa del Sistema de Evaluación de Impacto Ambiental.

Por lo tanto, tenemos que durante el desarrollo de procesos de evaluación de impacto ambiental de proyectos que impliquen la dictación de medidas admi-

que pertenezca al Estado la propiedad de los minerales o de los recursos del subsuelo, o tenga derechos sobre otros recursos existentes en las tierras, los gobiernos deberán establecer o mantener procedimientos con miras a consultar a los pueblos interesados, a fin de determinar si los intereses de esos pueblos serían perjudicados, y en qué medida, antes de emprender o autorizar cualquier programa de prospección o explotación de los recursos existentes en sus tierras. Los pueblos interesados deberán participar siempre que sea posible en los beneficios que reporten tales actividades, y percibir una indemnización equitativa por cualquier daño que puedan sufrir como resultado de esas actividades".

48 Convenio No 169 OIT, art. 6 No 1 letra a): "Al aplicar las disposiciones del presente Convenio, los gobiernos deberán: a) consultar a los pueblos interesados, mediante procedimientos apropiados y en particular a través de sus instituciones representativas, cada vez que se prevean medidas legislativas o administrativas susceptibles de afectarles directamente". 
nistrativas que afecten o puedan afectar a pueblos indígenas o a sus miembros, el órgano a cargo de impulsar y dirigir los procesos de Consulta Indígena será el Servicio de Evaluación Ambiental. Organismo creado por el legislador, entre otras cosas, para administrar el instrumento de gestión ambiental Sistema de Evaluación de Impacto Ambiental.

Todo lo anterior, nos permite señalar que la institucionalidad ambiental no cumple con el imperativo que la consulta efectivamente sea previa, ya que ésta, como se concibe, no da espacio ni lugar a la consulta en las etapas de planificación previas y o iniciales, esto es, antes de que el proyecto entre al Sistema de Evaluación de Impacto Ambiental.

\subsubsection{La Consulta debe responder a la cultura del pueblo indígena que se consulta y deben usarse procedimientos adecuados}

Que la Consulta responda a la cultura del pueblo indígena al que se consulta y coherentemente con ello que se usen procedimientos adecuados, parece estar ausente en el D.S. No 66 , toda vez que en el artículo $8^{\circ}$ inciso $1^{\circ}$ del Reglamento se establece que las resoluciones de calificación ambiental se consultarán de acuerdo a la normativa del Sistema de Evaluación de Impacto Ambiental, dentro de los plazos que tal normativa establece, pero respetando el artículo 16 del presente instrumento en lo que se refiere a las etapas de dicha Consulta, es decir, ni cercana búsqueda de respeto por la cultura de los pueblos consultados, ni esbozos de un procedimiento adecuado a las formas y manifestaciones del pueblo que se consulta.

El D.S. No 40, para el Sistema de Evaluación de Impacto Ambiental, por su parte, establece que si el proyecto o actividad lo ameritan, ¿quién hace la definición del mérito?, no un diálogo entre el pueblo indígena y el Servicio de Evaluación Ambiental, ya que aparece como una facultad discrecional de la Administración determinar el mérito; aun cuando se deberá, de conformidad al inciso segundo del artículo $4^{\circ}$ de la Ley No 19.300, "diseñar y desarrollar un proceso de consulta de buena fe, que contemple mecanismos apropiados según las características socioculturales propias de cada pueblo y a través de sus instituciones representativas, de modo que puedan participar de manera informada y tengan la posibilidad de influir durante el proceso de evaluación ambiental. De igual manera, el Servicio establecerá los mecanismos para que estos grupos participen durante el proceso de evaluación de las aclaraciones, rectificaciones y/o ampliaciones de que pudiese ser objeto el Estudio de Impacto Ambiental. En el proceso de consulta a que se 
refiere el inciso anterior, participarán los pueblos indígenas afectados de manera exclusiva y deberá efectuarse con la finalidad de llegar a un acuerdo o lograr el consentimiento. No obstante, el no alcanzar dicha finalidad no implica la afectación del derecho a la consulta”.

Esta es una manifestación de que el Servicio de Evaluación Ambiental posee la facultad para crear procedimientos particulares, con los serios riesgos de que estos procedimientos no respeten las formas culturales de los pueblos indígenas a ser consultados y por ello se constituyan en procedimientos inadecuados, ya que no hay norma reglamentaria alguna que establezca y garantice un diseño para que ello no ocurra. Curiosamente, la norma reglamentaria sólo establece principios generales, cuestión normalmente impropia de una norma reglamentaria. No es suficiente garantía el que la norma señale que no se deba omitir lo preceptuado en los títulos II y III del D.S. No 66.

Una manifestación de que los procedimientos que establece el Reglamento de la Consulta no son adecuados y no respetan la cultura de los pueblos indígenas es que "cada una de las etapas deberá ser ejecutada en un plazo no superior a 20 días hábiles. Sin perjuicio de lo anterior, el órgano responsable de la medida, previo diálogo con las instituciones representativas de los pueblos indígenas susceptibles de ser afectados directamente, podrá, en la etapa de planificación, modificar los plazos señalados por motivos justificados, considerando la necesidad de establecer procedimientos flexibles que se adecuen a las circunstancias propias de cada consulta en particular" ${ }^{49}$. Ello supone desconocer o no reconocer la dinámica propia de los pueblos indígenas para quienes ese es un plazo exiguo. Los tiempos del hombre blanco no son los tiempos del hombre indígena, quienes tienen una conexión diferente con la tierra y con los procesos que la involucran.

49 D.S. No 66 art. 17: "Plazos. Las consultas de las medidas administrativas o legislativas susceptibles de afectar directamente a los pueblos indígenas, considerarán los siguientes plazos de acuerdo a las etapas establecidas en el artículo anterior: a) Tratándose de medidas legislativas que se deban iniciar por Mensaje del Presidente de la República, cada una de las etapas deberá ser ejecutada en un plazo no superior a 25 días hábiles. b) Tratándose de medidas administrativas, cada una de las etapas deberá ser ejecutada en un plazo no superior a 20 días hábiles. Sin perjuicio de lo anterior, el órgano responsable de la medida, previo diálogo con las instituciones representativas de los pueblos indígenas susceptibles de ser afectados directamente, podrá, en la etapa de planificación, modificar los plazos señalados por motivos justificados, considerando la necesidad de establecer procedimientos flexibles que se adecuen a las circunstancias propias de cada consulta en particular". 


\subsubsection{Instituciones representativas y buena fe}

Otro aspecto que aparece como vulnerado por el Reglamento es que la consulta debe hacerse a través de las instituciones representativas de los pueblos indígenas. Sin embargo, este principio no está tan claro, según a continuación se explicará:

¿Dónde parece estar la incongruencia? En que, por una parte, el artículo $6^{\circ}$ del Reglamento correctamente señala la facultad de los pueblos indígenas de determinar libremente sus instituciones representativas; pero no obstante ello, desconoce en ellas el consentimiento previo, libre e informado de que disponen los pueblos indígenas como un recurso para cautelar sus derechos y así se les niega capacidad y facultad para decidir su futuro, ya que los pueblos son consultados en una situación de total subordinación al Estado. No respetando de este modo la autonomía y libre determinación de los pueblos a la que obliga el Convenio No 169 de la OIT50.

Así queda claramente establecido en el art. $3^{\circ}$ del Reglamento, que señala que se tiene cumplido el deber de consultar, aun cuando no resulte posible alcanzar dicho objetivo, refiriéndose al acuerdo o el consentimiento de los pueblos afectados ${ }^{51}$. Lo mismo aparece dicho en el art. 85 inciso 2 del D.S. No 40 que señala: "En el proceso de consulta a que se refiere el inciso anterior, participarán los pueblos indígenas afectados de manera exclusiva y deberá efectuarse con la finalidad de llegar a un acuerdo lograr el consentimiento. No obstante, el no alcanzar dicha finalidad no implica la afectación del derecho a consulta". Aun cuando es claro que el Convenio No 169 de la OIT va en la dirección inversa a lo establecido en los recién mencionados art. $3^{052}$ y 85 inciso 2.

50 Convenio No 169 de la OIT, art. 7 No 1: "Los pueblos interesados deberán tener el derecho de decidir sus propias prioridades en lo que atañe al proceso de desarrollo, en la medida en que éste afecte a sus vidas, creencias, instituciones y bienestar espiritual y a las tierras que ocupan o utilizan de alguna manera, y de controlar, en la medida de lo posible, su propio desarrollo económico, social y cultural. Además, dichos pueblos deberán participar en la formulación, aplicación y evaluación de los planes y programas de desarrollo nacional y regional susceptibles de afectarles directamente".

51 D.S. No 66 art. 30: "Cumplimiento del deber de Consulta. El órgano responsable deberá realizar los esfuerzos necesarios para alcanzar el acuerdo o el consentimiento de los pueblos afectados, dando cumplimiento a los principios de la Consulta a través del procedimiento establecido en este reglamento. Bajo estas condiciones, se tendrá por cumplido el deber de consulta, aun cuando no resulte posible alcanzar dicho objetivo".

52 Convenio No 169 OIT, art. 6 No 2: "Las consultas llevadas a cabo en aplicación de este Convenio deberán efectuarse de buena fe y de una manera apropiada a las circunstancias, con la finalidad de llegar a un acuerdo o lograr el consentimiento acerca de las medidas propuestas". 
Todo lo dicho hasta ahora pone en entredicho y genera una, ya ancestral y en opinión del autor fundada, desconfianza de los pueblos indígenas respecto del Estado en el sentido que éste efectivamente a través de la Consulta cree procedimientos e instrumentos que se funden en un principio de buena fe, con la finalidad de llegar a un acuerdo.

El logro del acuerdo es de la esencia de la Consulta, por lo que el Estado no puede circunscribirla a un simple procedimiento y estimar que no se afecta el derecho a la Consulta si no se logra su finalidad.

Finalmente, en el comentado Reglamento existen una serie de carencias que nuevamente dan cuenta de la falta de diálogo entre el Ejecutivo y los pueblos indígenas, y que se refleja en artículos que no son explicados de manera cabal, como por ejemplo:

a) No aparece completo el tipo de organismos del Estado que estarán normados o no por este decreto, como por ejemplo: Municipalidades, Indap, Conaf, Sernapesca;

b) No hay explicación alguna que permita comprender la referencia a las medidas administrativas regladas y no regladas ${ }^{53}$;

c) No queda claro el papel de la Consulta frente a normas legislativas y a la ratificación de convenios internacionales, ya que sólo se plantea la Consulta a medidas iniciadas por el Ejecutivo y no se refiere a las diferentes etapas de reformas que pueden sufrir los proyectos ${ }^{54}$

d) los plazos que señala el Reglamento son muy rígidos y ello no es compatible con las formas y lógicas culturales propias de los pueblos indígenas ${ }^{55}$.

53 D.S. No 66, art. 70 inciso 3: "Son medidas administrativas susceptibles de afectar directamente a los pueblos indígenas aquellos actos formales dictados por los órganos que formen parte de la Administración del Estado y que contienen una declaración de voluntad, cuya propia naturaleza no reglada permita a dichos órganos el ejercicio de un margen de discrecionalidad que los habilite para llegar a acuerdos u obtener el consentimiento de los pueblos indígenas en su adopción, y cuando tales medidas sean causa directa de un impacto significativo y específico sobre los pueblos indígenas en su calidad de tales, afectando el ejercicio de sus tradiciones y costumbres ancestrales, prácticas religiosas, culturales o espirituales, o la relación con sus tierras indígenas".

54 Abogabir (2014): "295. Otra debilidad identificada, es que algunos plantean la necesidad de que la consulta a los pueblos indígenas se regule por Ley, considerando la importancia de incorporar la consulta para los organismos autónomos como los Municipios, Tribunales de Justicia y el Congreso Nacional, los cuales no pueden ser regulados por estas normativas, pues solo regulan el ejercicio de los actos dictados por el poder ejecutivo".

55 Gundermann (2013), pp. 93-108. 


\section{CONCLUSIONES}

Por todo lo expuesto, podemos concluir que:

1. No cualquier acto de Consulta puede interpretarse como un acto que responde a la obligación de consultar que establecen, para los Estados, las normas internacionales.

2. La Consulta deberá cumplir con ciertos requisitos: que sea previa, que responda a la cultura del pueblo indígena consultado, deben usarse procedimientos adecuados, debe realizarse a través de instituciones representativas del o los pueblos, debe realizarse de buena fe y cumplir con el objetivo esencial de llegar a un acuerdo. El apego a estos requisitos son los que harán que el Estado chileno aparezca cumpliendo sus compromisos internacionales en materia de derechos humanos y de pueblos indígenas.

3. La Consulta como ha sido planteada por el Estado de Chile, en el D.S. No 66 de 2013 y en D.S. No 40 de 2013, no cumple con los estándares internacionales, ni con las condiciones que respecto de ella han establecido numerosos pronunciamientos de la Corte Interamericana de Derechos Humanos y de la Comisión Interamericana de Derechos Humanos.

4. El objetivo de la Consulta, no es otro que obtener el consentimiento libre e informado del pueblo indígena sobre las materias que les afectarán, por lo que no es posible que el Estado se satisfaga con cumplir con un determinado procedimiento, que en lo esencial nunca toma verdaderamente en cuenta las formas culturales como los pueblos indígenas discuten y deciden; del mismo modo, nunca llega a respetar la voluntad y la cosmovisión de estos pueblos.

\section{BiBLIOGRAFÍA}

\section{Normas nacionales}

Decreto Supremo No 124 de 2009, Ministerio de Planificación y Cooperación. Decreto Supremo No 66 de 2013, Ministerio de Desarrollo Social.

Decreto Supremo No 40 de 2013, del Ministerio de Medio Ambiente.

Ley No 19.300 de 13 de noviembre de 2010. Sobre Bases Generales del Medio Ambiente.

\section{Normas internacionales}

Convenio No 169 sobre Pueblos Indígenas y Tribales en Países Independientes. Organización Internacional del Trabajo. 
Declaración de las Naciones Unidas sobre los Derechos de los Pueblos Indígenas. 13 de septiembre de 2007 en la 61 a sesión de la Asamblea General de las Naciones Unidas.

Convención Americana sobre Derechos Humanos suscrita en la Conferencia Especializada Interamericana sobre Derechos Humanos, San José de Costa Rica, noviembre de 1969.

\section{Jurisprudencia internacional}

Corte Interamericana de Derechos Humanos. Caso Yatama vs. Nicaragua. Sentencia de 23 de junio de 2005.

Corte Interamericana de Derechos Humanos. Caso Saramaka vs. Surinam. Excepciones Preliminares, Fondo, Reparaciones y Costas. Sentencia de 28 de noviembre de 2007.

Corte Interamericana de Derechos Humanos. Caso del Pueblo Saramaka vs. Surinam. Interpretación de la Sentencia de Excepciones Preliminares, Fondo, Reparaciones y Costas. Sentencia de 12 de agosto de 2008.

Corte Interamericana de Derechos Humanos. Caso Kincha de Sarayaku con Ecuador. Sentencia de 27 de junio de 2012.

\section{Informes}

CIDH, Informe No 40/04, Caso 12.053, Comunidades Indígenas Mayas del Distrito de Toledo (Belice), 12 de octubre de 2004.

CIDH, Democracia y Derechos Humanos en Venezuela. Doc. OEA 54, 30 de diciembre de 2009.

CIDH, Informe de Seguimiento - Acceso a la Justicia e Inclusión Social: El camino hacia el fortalecimiento de la Democracia en Bolivia. Doc. OEA. 40, 7 de agosto de 2009.

CIDH, Segundo Informe sobre la Situación de los Derechos Humanos en el Perú. Doc. OEA 59 rev., de junio de 2000, Capítulo X.

CIDH, Acceso a la Justicia e Inclusión Social: El camino hacia el fortalecimiento de la Democracia en Bolivia. Doc. OEA 34, 28 de junio de 2007.

ONU - Consejo de Derechos Humanos - Informe del Relator Especial sobre la situación de los derechos humanos y libertades fundamentales de los indígenas, James Anaya. Doc. ONU, 15 de julio de 2009. 
6. Pueblos Indígenas y los ODM. PUND Colombia. 2014. Fondo para el logro de los ODM.

\section{Artículos}

Abogabir, Matías (2014): "Estudio de caso Chile. Convenio 169 de la OIT y la consulta a los pueblos indígenas en los proyectos de inversiones". Oficina Internacional del Trabajo.

Aguiar, Gonzalo (2006): "La aspiración indígena a la propia identidad". Revista Universum (V. 21 No 1), pp. 106-119.

Alva, Amelia (2014): "El derecho a consulta previo de los pueblos indígenas en Derecho”. Cuadernos Deusto Derechos Humanos (No 76), pp. 77-78.

Aninat, Isabel (2014): "Desafíos pendientes del Convenio 169". Edición online No 369 en www.cepchile.cl.

ConTesse, Jorge (2012): "El derecho de consulta previa en el Convenio 169 de la OIT. Notas para su implementación”. (Santiago. Ediciones Diego Portales). Gundermann, Hans (2013): "Procesos étnicos y cultura en los pueblos indígenas de Chile”. (Alpha No 36), pp. 93-108.

Henríquez, Alfonso (2013): "Participación Indígena: desarrollo y alcances en torno a la participación ambiental”. Revista Ius et Praxis (año 19, № 2, 2013).

Leppe, Juan (2015): "Consulta indígena y procedimiento de evaluación de impacto ambiental. Análisis de una relación normativa". Revista de Derecho de la Pontificia Universidad Católica de Valparaíso (XLIV), pp. 369-383.

TorreCuAdrada, Soledad (2010): "La Declaración de las Naciones Unidas sobre los derechos de los pueblos indígenas: antecedentes, consecuencias y perspectivas". Revista de Estudios Internacionales (Vol. 42, No 165).

Trentavizi, Bárbara (2011): "Las consultas comunitarias de buena fe contra la minería y proyectos extractivos en Guatemala: un expresión de ciudadanía”, pp. 5 a 7. En: actacientifica.servicioit.cl/biblioteca/pn/PN1/P1_TrentaviziB.pdf. URRUTIA, José: "Principales aspectos relativos a la implementación del Convenio No 169 de la OIT". Estudios jurídicos de aproximación del derecho latinoamericano y europeo, pp. 327-335.

\section{Internet}

www.radiouchile.cl, 23 de noviembre de 2013: "Comunidades critican firma del Reglamento de Consulta Indígena: Es un acto de mala fe”. 
www.semillasdeagua.cl. "Pueblos originarios rechazan decretos 66 y 40 impulsados por gobierno para sacar la consulta indígena".

www.mapuexpress.net, 31 de febrero de 2009: "Aymaras califican como un acto de mala fe la pseudo consulta que realizan Conadi y el Comisionado".

INDH, agosto 2011. "Deber de Consulta Pueblos Indígenas". En www.bibliotecadigital.indh.cl.

http://www.politicaspublicas.net/panel/c169noticias/742-declaracion-encuentromayo2011.html.

Solicitud directa de la Comisión de Expertos de la OIT, http://www.politicaspublicas.net/panel/chile-oit/737-ceacr-solicitud-directa-chile.html.

Declaración pública de autoridades ancestrales y dirigentes de los pueblos indígenas, 2014, http://www.indh.cl/declaracion-publica-de-autoridades-ancestralesy-dirigentes-de-los-pueblos-indigenas-autoconvocados\#sthash.xwRY4am9. dpuf.20, numerales romanos I y II.

Comisión Jurídica para el autodesarrollo de los pueblos originarios andinos. Marzo, 2010. Nos. 11,12,13,17 y 19, en www2.ohchr.org7english/issues/ indigenous/.../3rd/docs/.../MEDPS.doc. 